\title{
(In)visible Ghosts in the Machine and the Powers that Bind: The Relational Securitization of Anonymous
}

Journal Article

Author(s):

Dunn Cavelty, Myriam (1); Jaeger, Mark Daniel

Publication date:

2015-06

Permanent link:

https://doi.org/10.3929/ethz-b-000101904

Rights / license:

$\underline{\text { In Copyright - Non-Commercial Use Permitted }}$

Originally published in:

International Political Sociology 9(2), https://doi.org/10.1111/ips.12090 


\title{
(In)visible Ghosts in the Machine and the Powers that Bind: The Relational Securitization of Anonymous ${ }^{1}$
}

\author{
Myriam Dunn Cavelty and Mark Daniel Jaeger
}

ETH Zurich

\begin{abstract}
This paper analyzes the formation and subsequent securitization of the digital protest movement Anonymous, highlighting the emergence of social antagonists from communication itself. In contrast to existing approaches that implicitly or explicitly conceptualize Othering (and securitization) as unidirectional process between (active) sender and (passive) receiver, an approach that is based on communication gives the "threat" a voice of its own. The concept proposed in this paper focuses on "designations" as communicating rules and attributes with regard to a government object. It delineates how designations give rise to the visibility of political entities and agency in the first place. Applying this framework, we can better understand the movement's path from a bunch of anonymous individuals to the collectivity "Anonymous," posing a threat to certain bases of the state's ontological existence, its prerogative to secrecy, and challenging its claim to unrestrained surveillance. At the same time, the state's bases are implicated and reproduced in the way this conflict is constructed. The conflict not only (re)produces and makes visible "the state" as a social entity, but also changes or at least challenges the self-same entity's agency and legitimacy. Such a relational approach allows insights into conflict formation as dynamic social process.
\end{abstract}

Over the past few years, the name "Anonymous" has become associated with a new form of global protest, one that uses digital interruption campaigns and computer break-ins with subsequent release of sensitive information as modus operandi (Coleman and Ralph 2011; Olsen 2013). Beyond its slogans ("We are Anonymous. We are Legion. We do not forgive. We do not forget. Expect us."), its use of Guy Fawkes masks, and its (sometime) orientation toward issues of censorship, information freedom, and anonymous speech, the movement resists straightforward definition and classification. Shrouded in deliberate mystery and born of anonymity in a time obsessed with surveillance as ostensible enabler of

\footnotetext{
${ }^{1}$ We are grateful to the anonymous reviewers and the editors of International Political Sociology for their thoughtful comments that helped us to substantially improve the quality of this piece. Earlier versions of the paper were presented at the ISA Annual Convention 2013 and the EISA Pan-European Conference 2013. We would like to express our gratitude to members of the audience and especially to the discussants at these events, Halvard Leira and Juha Vuori, for their insightful comments.

Dunn Cavelty, Myriam and Mark Daniel Jaeger. (2015) (In)visible Ghosts in the Machine and the Powers that Bind: The Relational Securitization of Anonymous. International Political Sociology, doi: 10.1111/ips.12090 (c) 2015 International Studies Association
} 
political control, it purports to have no leaders, hierarchical structure, or geographical epicenter. However, despite, or rather because of, its elusiveness, together with its targeting behavior and communication practices, the movement has become a symbol for one of the twenty-first-century challenges to the security of many states: cyber-threats.

While Anonymous is certainly not the sole reason for the sustained, worldwide attention that network intrusions and disruptions are receiving, it nevertheless plays an intriguing and hitherto little researched part in it. Several aspects of its emergence as a collectivity (with ascribed political agency or status as a political actor) and, ultimately, national security threat are noteworthy. Most importantly, Anonymous does not just passively emerge as a threat by state designation, but is actively taking part in its own securitization by forcefully undercutting the state's prerogative to secrecy and authoritative information. Moreover, it also suggests and successfully establishes counter-securitizations, in which the state is presented as the main threat. Therefore, this political conflict is itself characterized, fueled, and sustained by conflicting meaning-making, in which a process of reciprocal securitization is serving a complex and curious identity function on both sides of the social conflict. On the one hand, Anonymous moves toward a set of well-established national security discourses, most notably the master discourse of terrorism. By thus encountering very specific state responses, the emergence of Anonymous as political actor first and foremost reinforces a view of the entity commonly referred to as "the state" as rule enforcer or punisher. However, the same emergence also changes, or at least challenges, stable notions of the state, albeit more subtly by adding a moment of self-reflection and by making fault lines appear within it.

Given these observations, we aim to trace and analyze the complex emergence of this digital (non-)entity-which proclaims itself to be "a collective of people with too much time on their hands, a commune of human thought and useless imagery ... a gathering of sheep and fools, assholes and trolls, normal everyday netizens" 2 - particularly in its transformation into a political actor, to which some people ascribe the ability to pose a grave threat to national security. ${ }^{3}$ We also want to understand how "the state" is itself implicated, (re)produced, and possibly changed in and through this securitization. In order to do so, we conceptualize the securitization of this protest movement as a dynamic, complex, relational struggle over threat-making and meaning-making, which shapes the antagonistic actors involved.

Much critical International Relations (IR) literature has focused on how states position themselves with regard to other states (or groups) and how this conceptualization of Self/Other (so-called "Othering") has constitutive effects on the notion (or identity) of the Self (cf. most prominently, Campbell 1992), often with security implications. However, the process of Othering in IR is mostly analyzed as a unidirectional process, in which the Other does not play an active role; Othering works as a mere projection. The same can be said for securitization studies. Most approaches to securitization presuppose bounded "communities" as political entities and then investigate securitization as discursive practices of communication unfolding within them. Potential security issues might be taken to lie inside such communities or outside of them but, in any case, they are assumed to be passive projections which do not actively partake in discursive practices. In other words, dangers do not communicate-agency remains

\footnotetext{
${ }^{2}$ Anonymous/Original. Available at https://encyclopediadramatica.se/Anonymous/Original. (Accessed August 8, 2014.)

${ }^{3}$ For example, Ex-NSA director General Keith Alexander reportedly said: "A stateless group like Anonymous doesn't yet have that capability ... But if the group's members around the world developed or acquired it, an attack on the power grid would become far more likely" (Wall Street Journal 2012).
} 
(pre-)assigned to known communities or to particular actors within them. These approaches thus largely overlook how relational processes of contestation are generative of the visibility of antagonistic entities and observed agency in the first place.

We break with this orthodoxy and purport that conflict constellations merit a conceptualization of threats not as passive projections, but as active participants. They partake in the production of antagonistic relationships, characterized by relational meaning contestations that make opponents visible. In the first section, we introduce a theoretical framework that permits studying the relational securitization we observed. In order to not simply distinguish by actors but rather by what takes place as a property of the communication or relation between them, we use the concept of designations. It builds on an understanding of communication as social process (Luhmann 1995) and on relational sociology, both of which discourage the reduction of complex processes to steady states (Emirbayer 1997).

Designations communicate rules and attributes constituting a "governance object" (cf. Corry 2013). As socially binding propositions, designations establish relations in a twofold way: first, between a governance object and a social entity subscribing to them and, second, between this entity and other social entities subscribing to different, competing designations concerning the governance object. Competing designations, in turn, are constitutive of the conflict in which these entities/collectivities emerge as opponents. In the second section, we look at the emergence of Anonymous as a political actor and security threat. We will show the unfolding process of "anonymous" individuals becoming "Anonymous," the collectivity, finally seen as posing a threat to certain bases of the state's ontological existence, while these bases are at the same time reproduced in the particular way the conflict is constructed. In conclusion, we reflect on the broader epistemological and political implications of what we have observed.

\section{Competing Designations and Securitization}

Acts of "Othering" as a part of mutual (identity) constructions of the Self and the Other are a central focus of different variants of (critical) security studies (cf. Der Derian 1990; Campbell 1992; Doty 1996; Neumann 1999). However, the model of communication these studies are based on comes with two limitations. First, even though most studies employ a language of "interrelatedness" between entities in such construction processes, they assume bounded (and fixed) political collectivities who shape the world of politics around them by projecting representations of difference onto other (passive) collectivities (who in turn do the same). Second, there is a predominant emphasis on political agency, without much reflection on its conditions of possibility. Conceptualizing dangers as projections centers the analysis on the (securitizing) agents - the speakers - and concomitants of such projections. In consequence, conflict escalation often appears as an intentional communicative act, making it difficult to understand how situations might unintentionally deteriorate. Yet focusing on authorship, be it of state officials or security bureaucracies, largely neglects how relational processes of contestation generate the visibility of antagonistic entities and construct agency in the first place.

These conceptions reject a sender-receiver model of communication to the extent that there is no communication beyond bounded collectivities at all. Like prisoners interpreting shadows in Plato's cave, they only know self-referential projection. The same goes for securitization studies, with their aim of understanding the processes that turn political issues into security issues (Buzan, Wæver and de Wilde 1998; Balzacq 2005). We find a similar treatment of "that 
which threatens," which is not given a voice of its own, and does not actively partake in discursive practices. The merits of these approaches lie in highlighting that perceived threats are inherently socially constructed. However, the question remains: Who is actually partaking in this construction? Frequently, constructed dangers are not passive and they are not silent. To the contrary, they can play a very active role in the securitization process and one, as we argue, that should be further unpacked to understand conflict dynamics, especially their early formation and escalation/de-escalation.

We therefore propose an understanding of securitization that takes up what was once central to social constructivism - the primacy of the relational-and builds on the tradition of sociological thinking that emphasizes the emergent quality of entities. Rather than taking social order in terms of rules or structures as point of departure, it treats relations as "prior to either individual agents or aggregate structures" (Nexon 2010:100). In other words, social relations, based on communication, constitute things. Political entities such as groups, actors, states, and governance objects emerge, along with their meaning and their eventual boundaries, as social facts in their being (re)produced in social relations (Emirbayer 1997:287). This approach differs from existing conceptualizations of Othering or speech acts to the extent that it conceives of action as part of communication, not the other way around (Albert, Kessler and Stetter 2008:56). In this section, we show how this works. First, we delve deeper into the relationship between communication, relations, and the emergent quality of social entities. Second, we describe how politics is fundamentally about generating (collectivity binding) designations. Third, we say a few words about the specific context in which we employ this framework of analysis.

\section{Social Relations through Communication: The Basics}

We purport that relations are established in communication, suggested by Niklas Luhmann as a basic denominator of social reality. Communication generates meaning and entities. Meaning is un-owned. "Authors" do not have outright power over meaning; it does not travel unambiguously to an addressee, as between pregiven sender and receiver. There is no unequivocal understandingrather there is double contingency between message and understanding of communicated information. Communication based on Luhmann's concepts results from the interplay of these three specific elements.

This notion differs in two important aspects from the limited communication model used in many poststructuralist studies. First, a mutual orientation of communicating entities cannot be presumed. Authors and addressees only emerge from completing a three-step sequence (Luhmann 1995:137-150): (i) any communication seeks to impose a meaning as part of its particular message, and it evokes a specific understanding; (ii) based on this understanding, it is either accepted or rejected in the follow-up operation which again evokes understanding; and (iii) this leads either to consensual meaning or to a conflict. Initially, there is no requirement of an intention to communicate something-decisive is the "backward" construction thereof as part of a specific understanding. There is double contingency and double emergence, creating a relation in orienting the involved as authors and addressees toward each other as entities.

Second, an "addressee" produces communication and meaning as much as an "author" does. Neither "message" nor "understanding" is ontologically privilegedthere is no "true" message and "true" understanding. Communication, its meaning, results from the unity of difference between information, message, and understanding. Both authors and addressees contribute equally to the specific meaning emerging out of a communication process (Albert et al. 2008). 
In consequence, there is no speaker-audience relation wherein a pre-destined and passive audience accepts or rejects the unequivocal message of a pre-given speaker. The speaker-audience distinction is artificial and analytically misleading. Communication is more than the sum of its parts. Therefore, social actions cannot be reduced to individual agents since they are interpreted, re-ascribed, distorted, and "socially overshaped" in highly contingent ways (Lohse 2011:199). Speech acts do not exist on the merits of an intentional individual actor, but because communication establishes relations, authorship, and agency as specific meaning (cf. Jackson and Nexon 1999).

By implication, neither a preexisting political actor nor a supposed opponent establishes antagonisms as they, along with the antagonism itself, emerge from mutually contingent interpretation processes. With this relational component, emerging opponents actively partake in securitization. Dangers, far from being merely passive projections, are linked to an evolving antagonistic relation. Yet an essential part of communication lies in establishing entities. It is only when entities attain "visibility" that they may acquire actor qualities in social relations as authors and addressees. ${ }^{4}$ Below, we theorize how a new entity emerges as antagonistic agent in contingent communication, partaking in its construction as danger and itself constructing dangers.

\section{The Politics of Designations}

Based on the systems theoretical ideas of Armin Nassehi (2002), we argue that entities emerge politically in communication through collectivity-binding designations concerning a governance object. Designations communicate propositions which socially bind collectivities as they subscribe to the constitutive attributes and rules on legitimacy, legality, and authority that make up a governance object. There is thus a conceptual double relation between constituting an entity and a governance object, to the extent that it becomes "co-constitutive of their identities" (Corry 2013:90). ${ }^{5}$

Conceptually, it is not the self-constituting authorship of a speaker that produces designations and addressees-designations constitute governance objects and entities. Designations as meaning imposition aim to communicate general validity concerning their key aspects. Therefore, they are always relational. However, entities only become visible as a consequence of designations in a social environment not subscribing to identical rules and attributes concerning governance objects. It is to this extent that social relations constitute entities (see Figure 1).

Designations constituting entities and governance objects may largely overlap, resulting in entities with distinct, but largely compatible visions. With communicated designations, there is "difference" but not direct "Othering" involved. Designations may change the meaning of a governance object and, through their co-constitutive force, the identity of relating entities as well. As a result, entities' identities are also influenced by other designations concerning a governance object. As a crucial consequence, this conception permits emphasizing the contingency of social entities.

In this approach, political power consists in the capacity to bind collectivities (Nassehi 2002:45-49). Such power may, but does not necessarily, presuppose coercion and does not assume a preexisting, intentional agent. Power relies on the visibility of a collectivity which, in case of contradiction, subscribes to a specific designation. Once an entity becomes visible, it can be addressed, reflexively

\footnotetext{
${ }^{4}$ Of course there are countless well-established authors, but they are constantly re-produced in social relations.

${ }^{5}$ Olaf Corry's interest is in social order evolving around governance objects. We are interested more specifically in theorizing the emerging relations unfolding between governance objects and entities.
} 


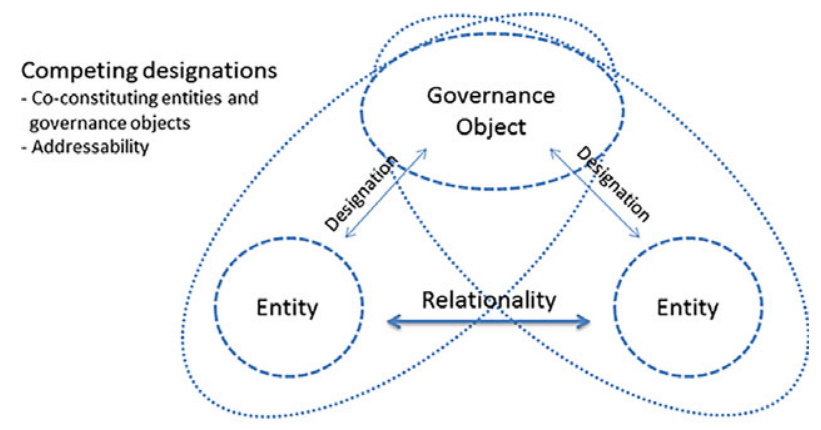

Hypothetical situation: Competition-free designation

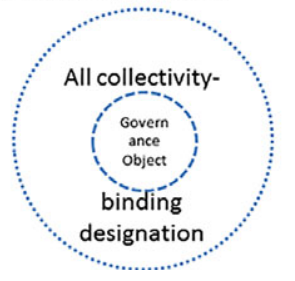

FIG 1. Designations: Constituting Governance Objects and Entities

in its own communication and relationally in communication with other entities, as a precondition of agential power. Entities can then be governed as well. Communicated designations seeking to forcefully bind a contradicting entity effectively aim to turn that entity into a governance object. By submitting, an entity will lose its status as an agent in communication.

In terms of communication this first, constitutive phase evolves into a second phase of unfolding relations, which involves established (visible) entities oriented toward a governance object. Designations may still be compatible. However, there might also be competing designations, giving rise to a conflict between entities. Initially, communicated designations expect acceptance. Rejection constitutes the Other in conflict, an Other who advances competing designations. Relations communicating competing designations between visible entities consist of constitutive incompatibilities concerning the meaning of governance objects, and hence of these entities themselves. In effect, such communication of contradiction and opposition politicizes existing designations and thus discloses underlying power relations which may have remained implicit.

When designations constituting entities' identities are questioned, a conflict may escalate, leading to opponents partaking in relational securitization. As Messmer (2007:104) argues, "it is less the particular content that influences the course of a specific conflict but rather the particular form ... expressing the contradiction." Based on Messmer's conflict model, we distinguish different ways of communicating conflict, in terms of either interest or identity incompatibilities (Diez, Stetter and Albert 2006). Compatible designations limit contradiction and opposition to issues that are trivial, in the sense that they can be reduced to interest incompatibilities. By contrast, competing designations that mutually question or exclude the identity and legitimacy of an opponent as an entity, defined by its relation to the contested governance object, give rise to antagonistic relations and to constructing opponents as danger, thereby securitizing the conflict (Messmer 2007). Once a conflict stabilizes in its orientation toward opponents, repeated communication of mutually exclusive designations invites them to construct their identities against each other-the well-known 
"Othering," albeit with the difference that the "Other" actively partakes in its own securitization.

\section{The State and Protest}

In this paper, we investigate the emergence of a specific protest movement as part of a relational antagonism. Protest movements are particularly well suited to trace the emergence of political entities from relational processes in communication since their early formation phase allows studying the establishment of visibility and addressability and then the workings of designations (McAdam, Tarrow and Tilly 2001:159). That being said, new conflicts and relational antagonisms emerge against a dense net of existing designations which are expressive of a configuration of existing entities (such as states) and their stakes in these designations (Jackson and Nexon 1999). In other words, whereas new emergent entities might be pure derivatives of antagonistic relations, "old" political collectivities (such as the United States) are not emergent to the same extent, but are nonetheless continually reproduced and even changed by a particular conflict.

This paper is particularly interested in the last phase described above: the securitization of relations and conflict (beyond mere interest incompatibilities). If one of the parties is "a state," then the antagonism inevitably evolves along somewhat familiar trajectories. As mentioned, competing designations mutually question or even exclude the legitimacy of an opponent as an entity. Due to the stable designations with regard to intentions, actions, and powers given to the state, such an antagonism then starts evolving around one or several instances of a state's ontological existence (cf. Mitzen 2006). Most significantly, this regards the reproduction of the state in its (ascribed) right as political sovereign and holder of the monopoly of violence. As part of that, it regards the state's (unilateral) power to designate (and defend) a territory as well as to both define and enforce the rules that need to be followed with regard to a governance object. Once an entity is given "security importance," its status has implications for the reproduction of "the state" as sovereign political entity and its ability to bindingly designate collectivities (cf. Onuf 1991; Luhmann 2000). The multifaceted challenge to this "right" through protest movements is at the heart of the political conflict we are interested in.

Furthermore, the ascribed powers of "the state" are manifest in how it affects orientations in designations overall, and specifically in how restricted competing designations are. Already existing designations in relation to a governance object produced by the state act like powerful magnets in any emerging conflict. If becoming a visible political collectivity means establishing constitutive incompatibilities concerning the meaning of governance objects, then entering into such a relation with the state always means reacting to designations that are already well-established by, and around, the state; and thereby always also reproducing a particular image of the state.

\section{The Securitization of Anonymous as Relational Antagonism}

In this section, we show how a focus on the relational constitution of Anonymous and on designations adds to our understanding of social conflict. We demonstrate how designations with regard to cyberspace (as governance object) lead to the visibility of an entity - and how "Anonymous" thus emerged as an addressee. We then show how competing designations turned opponents against each other and how the conflict became securitized-and we show how this conflict is constitutive of the conflict parties who actively (though not always intentionally) take part in their own securitization. 
What and where is a/Anonymous? In a very real sense, and not just on conceptual grounds, there is no direct access to this entity, but we do have access to (some) relevant communication about it. Many different (emergent and more stable) entities are involved in communicating about "Anonymous" in multiple ways. In other words, the history of Anonymous is the history of its ascribed actions, observations of these actions, and the media magnification of it. ${ }^{6}$ Forms of expression to observe designations are written statements (press releases, online statements, etc.); visual content (YouTube videos, images); secondary literature (academic and press material on Anonymous and the relation between the state and Anonymous); speech (as reported in the media); and, importantly, attributed deeds ("actions") and their communicative meaning.

In a first subsection, we look at the beginnings of Anonymous and focus on the emergence of Anonymous as visible political entity in the second. In the third, we look at how mutual referencing occurred in the conflict space and how antagonisms between "Anonymous" and "the state" became securitized, against the backdrop of how the collectivity-binding designations that continuously reproduce the state also extend to cyberspace. The resistance to such meaning imposition efforts is a basic aspect of the relational antagonism that subsequently emerged. This becomes apparent when Anonymous is presented as a threat to certain bases of the state's ontological existence, while these bases are at the same time reproduced in the particular way the conflict is constructed. In the fourth subsection, we show how Anonymous exposes the limits of state power and how the creation of "visibility" of the involved designations is a key political issue.

\section{The Superiority of Lulzing Trolls}

The social conflict, through which "Anonymous" emerges, hardly appears as an inevitable or intentional development. Rather, its roots are found in a primordial ooze that gave rise to a mode of expression exhibiting specific rules and attributes centered on two elements. First, some roots of Anonymous can be traced back to a particular, in itself purely technical, software configuration of a text board called 4chan, with the Random board being the most "famous" subsite, known as $/ \mathrm{b} /$. The particular software used on 4chan, and the many other "chans" that followed, invites users to behave in particular ways and is the background for an unfolding process of "anonymous" individuals becoming "Anonymous," the collectivity. Thus, the site itself requires no registration for participation, and there is not even a need to choose a nickname. ${ }^{7}$ If left blank, the site automatically assigns the default name "Anonymous" (over 90\% of all users use that option, see Bernstein, Lebow, Stein and Weber 2011).

Furthermore, posts are judged on the merit of their content rather than on the prominence or status of their author. ${ }^{8}$ Posts are extremely short-lived (ephemeral): the median life of a thread is 3.9 minutes, and it spends an average of 5 seconds on the first of 15 comment pages (Bernstein et al. 2011). If a post reaches the end of page 15, it expires and is deleted (forever). A post's

\footnotetext{
${ }^{6}$ It is noteworthy that many aspects of its emergence are not well documented, or not documented at all. For one discussion of this "problem" among people associated with, and interested in, one specific Anonymous activity, see the quite substantial Talk page associated with the entry about the so-called Habbo raids, an early collective activity of (a group of) Anonymous at http://en.wikipedia.org/wiki/Talk:Habbo. (Accessed August 8, 2014.) In particular, the Wikipedia entry caused (and continues to cause) problems because there were no "reliable sources" (that is, written material) to quote, which led to a discussion of the link between "official sources" and the "reality" of a phenomenon.

$7 / \mathrm{b} /$-board does not even ask for a name anymore; it is just assumed that a user will post as Anonymous.

${ }^{8}$ See interview with the founder of $2 \mathrm{ch}$, The Philosophy of $2 \mathrm{chan}$. Available at http://www.nihonreview.com/ forum/index.php?PHPSESSID=28a710b85414dd9251818552a2f8ffe7\&topic=333.0;wap2. (Accessed August 8, 2014.)
} 
position on the 15 pages is related to how much or little the particular content is appreciated by other users: it can be "bumped" (if somebody replies to a thread, it jumps back to first position) or "saged" (which moves it down to the end of page 15 faster). This leads to very high turnover and innovation in terms of content. Posting behavior (and content) on/b/is entirely disconnected from any stable identity which results in a disinhibited type of humor that is offensive and crude (to say the least), and operates at the expense of others. This type of Schadenfreude is called "lulz," and works best if the victim gets (very) angry. ${ }^{9}$

The second element of the emerging, specific mode of expression on the anonymous, ephemeral interaction at 4chan is the so-called (Internet) meme. Memes, in short, are ideas, concepts, patterns, words, hashtags, videos, pictures, etc., that spread through the Internet and gain a certain mass of followers/ reproducers (often in a "viral" way, that is, quickly and globally). Memes are usually short-lived but they often evolve, effectively building a particular web of meaning which is hard to understand for uninitiated people. Deep knowledge of 4chan's particular and interrelated meme culture, including a specific type of language and/or style (which changes all the time), is necessary to become a "member" of Anonymous (Underwood 2009). Memes thus play a central role in constituting the collectivity "Anonymous" as inhabitants of cyberspace.

The meaning of these two particular elements - the particular software configuration plus the meme culture-was a formative part of an emerging protodesignation that easily took hold. It established an early boundary, between an "inside" of belonging, of insiders subscribing to the cultural (and technical) rules and able to decode them, and an "outside," marked by absence of the same.

On a larger scale, however, there was no such thing as an "entity" Anonymous at this stage. "Anonymous" was merely an assignment made, analogous to that undertaken by many other electronic forums configured in a technically similar way. Increasingly however, effective links between these individual components were forged by integrating new elements and developed into something more discrete. By around 2006, observations of a larger, anti-individualistic collectivity appeared, when meme content from the 4chan community began to influence the larger Internet culture and became a mass phenomenon. ${ }^{10}$ To affiliate oneself with Anonymous at that time was to "announce your association with an esoteric brand of humor, a badge of pride and superiority" (Halupka 2011:39) superiority born out of a notion of being able to designate cyberspace better than others.

This emergent sense of anonymous collectivity was both nourished by, and led to, collective "raids," which marked the beginning of the first conflicting designations. A "raid" in Internet jargon is a term for "an organized assault on a Web site or forum by a group of trolls, normally designed to cause disruption on a large scale,"11 and troll or trolling is another jargon word for disruptive behavior in online contexts (Donath 1998). Raids were early forms of relational antagonisms. Raiders had no (common) political, ethical, philosophical, or moral agenda, yet they effectively performed a deviant designation of cyberspace. Done for "the lulz," trolling reflects the fundamental ideals of Anonymous as the capacity to incite grief (Underwood 2009:133fn.). Target selection, occurring in

\footnotetext{
${ }^{9}$ Many traits of the interactions on 4chan suggest that the majority of participants are middle-class white, male sub/urban Americans. Almost all threads on/b/are written in English, and often engage American culture and politics when they are not about Japanese anime/manga (Phillips 2013).

${ }^{10}$ By March 2010, the New York Times reported that the daily page view total was 800,000 and that the site had 8.2 million unique monthly visitors (Bilton 2010).

${ }^{11}$ Available at http://villains.wikia.com/wiki/Raid_\%28Internet\%29. (Accessed August 8, 2014.)
} 
a rather opaque decision-making process ${ }^{12}$ via the suggestion of collective action as "Anonymous" and the formation of adequate support on the/b/-board (Coleman 2011; Halupka and Star 2011), is linked to the expectation of an entertaining retaliatory response. What can be observed at this stage is an interesting interplay between the awakening "hive mind" as anonymous, decentralized mass and a particular image of a collectivity. Participants were most entertained by the notion that any retaliation would be ineffective since no one and everyone was part of Anonymous (Underwood 2009:20), and it could never be defeated, destroyed, or made obsolete and would continue to live on as an idea. The moniker Anonymous became part of a designation, evolving around the Internet as an anarchical, not-so social space.

As a logical consequence, nobody was safe from this relational antagonism; not even Anonymous' "home." A group of Anons attacked 4chan on "/b/-day," as a reaction to new rules put in place by 4chan administrator m00t, which forbade the use of the Web site for the organization of attacks. ${ }^{13}$ This "internal" relational antagonism around 4chan resulted in a kind of fission, the designation of 7chan (and "The Declaration of/b/Independence") as a new home for the old attack-willing "/b/tards" (the name given to the users of the/b/-board), and was the beginning of a type of tribalism. The collective existed as a decentralized, fluid network with a fluctuating participant base, and with participants discarding individualistic markers in order to function as a leaderless mass of trolls.

\section{Anonymous Becomes Visible}

It is impossible to know exactly when the adjectival form of anonymous gave rise to Anonymous as mass noun - a sign for a self-reflexive collectivity making an entity-but it seems clear it was in circulation by 2006 (Phillips 2013). By 2007, Anonymous had already spawned the Anonymous Credo (also "The Code of Anonymous") that initially opened with the claim "we are Anonymous, and we do not forgive" and continued with "We are void of human restraints, such as pity and mercy." 14 However, this "self-reflexive collectivity" is multifaceted, diffuse, and unstable. ${ }^{15}$

On July 27, 2007, Fox News aired its now infamous, catalytic "Report on Anonymous" which contained terms such as "hackers on steroids," "hacker gangs," and "the Internet hate machine," with one interviewee calling them "terrorists" accompanied by the image of an exploding service van. ${ }^{16}$ Unsurprisingly, this report was "a windfall for Anonymous" (Phillips 2013:7), with its terms and images immediately integrated into the memetic trolling culture. In a twisted way, Fox News was midwife to the emergence of a larger relational antagonism. In socially ascribing certain actions to Anonymous, Fox News provided for the visibility of Anonymous as an addressee and also presaged the outlines of an antagonism by ascriptions implying a particular kind of danger. At the same time, their observations contributed to establishing boundaries. In "reading" Anonymous through a designation of cyberspace which entirely missed out on

\footnotetext{
${ }^{12}$ The Anonymous-affiliated Encyclopædia Dramatica documents some of the trolling events and "raids." However, due to the nature of $4 \mathrm{chan}$, where old data are deleted, there is no way to reconstruct how target proposition is linked to "successful" collective mobilization into a raid or which suggestions did not gain sufficient support. It is also impossible to say what "sufficient" support is.

${ }^{13}$ https://encyclopediadramatica.se/B/-day. (Accessed August 8, 2014.)

${ }^{14}$ See Urban Dictionary at http://www.urbandictionary.com/define.php?term=\%22Anonymous\%22. (Accessed August 8, 2014.) This was changed to "Anonymous is devoid of humanity, morality, pity, and mercy" in a later version: http://qwertydeer.deviantart.com/art/The-Code-Of-Anonymous-106893238). (Accessed August 8, 2014.)

${ }^{15}$ One researcher humorously summarized Anonymous "ideology" as: "1. Do it for the lulz. 2. Internet censorship is bad. 3. Don't hurt cats" (Crenshaw 2011).

${ }^{16} \mathrm{http}: / /$ www.youtube.com/watch?v=DNO6G4ApJQY. (Accessed August 8, 2014.)
} 
the reflection of Anonymous by its participants, it added to the demarcation of the inside from the outside and at the same time strengthened a competing designation of Anonymous against the "inferior," the ones who do not know the Internet and/or take it too seriously. ${ }^{17}$

A further consolidation of Anonymous as publicly known Internet deviants came in 2008, when there were several noteworthy developments which ultimately contributed to Anonymous' securitization. They were set in motion by an "operation," now known as Project Chanology, spanning several months. Videos on YouTube announced Anonymous' agenda, ${ }^{8}$ along with a press release declaring "War on Scientology," stating that the Church's enforcement of censorship went against the collective's "moralist principles" and that information should be freely accessible. With the lulz still a key component, some scholars suggest that Anonymous saw its constructed public image as an elaborate joke, one which only the insiders would ultimately "get" (Underwood 2009; Halupka 2011). Anonymous successfully portrayed itself as "an altruistic group fighting for human rights and freedom of speech" (Underwood 2009:156), attracting the attention of both the international media and people with a similar agenda or inclination. This led to a considerable influx of new participants who became active over the course of Project Chanology. ${ }^{19}$ Electronic disruptions were not much different from the raids before, though bigger in scale (see Vichot 2009:23; also Underwood 2009; Halupka 2011). However, these online activities were soon followed by "flash mob" demonstrations in front of Scientology churches, ${ }^{20}$ resulting in a remarkable amount of media coverage for a protest which had recruited only a few thousand people worldwide.

As Halupka (2011:47) observes, "Latching onto the created persona, the media observed Anonymous as a loose knit community of cyber hackers who fought for freedom of information and anticensorship ideals" as part of an amorphous, widespread social awakening. Anonymous was effectively reflected in a public face. In a further designative symbolism, "Guy Fawkes" masks ${ }^{21}$ were widely adopted during the protests to hide people's faces (Elliott 2009). Not only did these masks become an unofficial symbol of the collective as political entity and addressee, it also constructed a public image that became firmly ingrained within the global perception. In addition, the memorable Anonymous logo - a suited figure with a question mark where his head should be, set against a UN-style globe (see Figure 2) -was now used for all "official" communications (Walker 2011). Anonymous was visualized as a virtual non-entity (Parikka 2009:111), as a faceless legion bound by a common designation. This visual branding may even have been essential in binding together people who resist being bound to anything, or anyone. Anonymous, the meme machine, was now a meme itself (Figure 3).

The wider politicization of Anonymous is about conflicting designations of cyberspace as a governance object. Its challenge to Scientology is the attempt to designate what is legitimate conduct (that is, electronic civil disobedience) and what is not (for example, censorship). In the emergence of mutual referencing, such meaning imposition was contested by Scientology, which sought to reject it by designating Anonymous as a different collectivity, as Internet terrorists (Jacobsen 2009).

\footnotetext{
${ }^{17}$ On how the relation between knowledge and social reality ultimately points to the power of designations, see Guzzini (2000)

${ }^{18}$ Message to Scientology. Available at http://www.youtube.com/watch?v=JCbKv9yiLiQ. (Accessed August 8, 2014.) Call to Action. Available at http://www.youtube.com/watch?v=YrkchXCzY70. (Accessed August 8, 2014.)

${ }^{19}$ This was most evident in the attacks on Web sites such as Digg and YouTube, where the Church filtered antiScientology comments. See also http://www.lisamcpherson.org/pc.htm. (Accessed August 8, 2014.)

${ }^{20}$ http://knowyourmeme.com/memes/events/project-chanology. (Accessed August 8, 2014.)

${ }^{21}$ Graphically, it is inspired by the film (and graphic novel) "V for Vendetta," in which a vigilante character wears such a mask while overthrowing a totalitarian British government in an imagined dystopian future.
} 


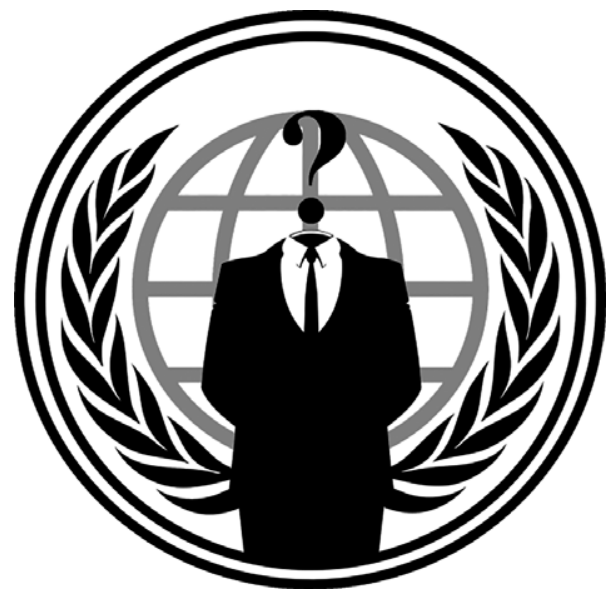

FIg 2. The "Official" Anonymous Logo

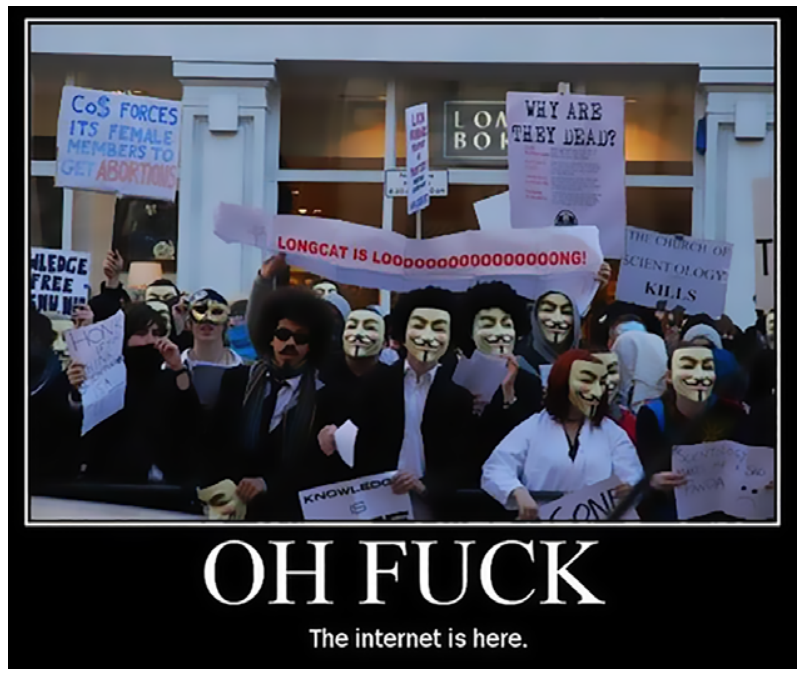

FIG 3. A Meme about a Meme

Ultimately, and importantly, the considerable influx of new participants into Anonymous during Operation Chanology led to a sort of schism between the Lulzers and the Moralists (consisting of new members and some old participants who were tired of "the lulz") - a significant re-designation of the collectivity. Anonymous thereafter became much more strongly associated with a hacker philosophy, against the censorship of Information, using new forms of activism in the process (Rolfe 2005). This resulted in activities such as Operation Didgerdie, Operation Titstorm, and a collaborative effort with the torrent housing Web site, The Pirate Bay, in support of the Iranian election protests (to name just a few). ${ }^{22}$ Even more importantly, in its continuous emergence, Anonymous was aligned with state cyber-designations.

\footnotetext{
${ }^{22}$ There were other protests being organized on the Internet almost concurrent with Project Chanology. For example, using Facebook and other online social tools, Oscar Morales organized protests against a terrorist group in Columbia known as FARC.
} 


\section{Mutually Exclusive Designations and Securitization}

Politically, the beginnings of antagonistic relations around designating cyberspace as a governance object can be located in the 1980s, when states designated this "new" space as object of (traditional) state governance. This understanding was contested by competing designations as a "new" and unchartered, uncivilized land (Mihalache 2002; Yen 2003), in which state power - that is, the ability to designate a territory and define and enforce the rules to be followed in a specific social space- has no (or at least very little) standing (Barlow 1996).

From this conflict emerge certain actors as part of a relational antagonism: socalled hackers (Nissenbaum 2004; Parikka 2007). This category contains a very diverse set of people, sometimes differentiated as black (bad) versus white (good) hat hackers, which makes any generalization about this group unviable (see Jordan 2008). Nonetheless, it can be said that a substantial part of this collectivity (including well-organized entities such as the free software movement; Coleman 2012b) reject designations of cyberspace as object of state governance either entirely, or to some degree. Competing designations of cyberspace often crystallize around what is known, loosely, as "hacker ethics" (Himanen 2001). These include access to computers for all; that all information should be free; and authority must be distrusted, also for security reasons (Levy 1984:xi). Importantly, the right to remain anonymous - and thus invisible, un-addressable, un-bindable - when moving in cyberspace is also a point often made.

In the particular social conflict that we are interested in, the merging of political activism with hacking ability, so-called Hacktivism, is particularly salient. Hacktivism as a form of resistance, a "micropolitics of code" (Parikka 2009:119), reaches back several decades; and so does the state's attention to it. Cyber-issues were given high priority in the 1990s, when they were established as fundamental to security, the economy, the way of life, and perhaps even the survival of the industrialized world (PCCIP 1997) - which established cyberspace as national security matter (Bendrath 2003). In turn, electronic civil disobedience emerged as part of a larger threat to the security of the online world (Lunceford 2012:51). Due to the ability of data networks to collapse time and space, attacks against them can be launched from anywhere in the world, and discovering their origin, if they are detected in time at all, remains a major difficulty. This "attribution problem" refers (technically) to the difficulty of clearly determining those initially responsible for a cyber-attack, plus the difficulty of identifying their motivating factors (Deibert and Rohozinski 2009). The technical attribution problem translates, first, into an attribution problem in theoretical terms, because that which is not visible and cannot be made visible dodges designation. Second, it translates into a political problem in challenging the enforcement of bindings: what cannot be bound cannot be punished. Much of the policy debate in this domain is therefore about how this visibility can be assured and the anonymity that cyberspace grants be reduced.

Faring on hacktivist principles, Anonymous as a visible political entity fully entered public consciousness in December 2010 with Operation Payback (Coleman 2012a). At first, Operation Payback comprised a wave of attacks on major procopyright and antipiracy organizations, law firms, and individuals. Several operations were ongoing, when competing designations about cyberspace escalated into a conflict about freedom of information, with WikiLeaks coming under intense pressure after challenging the state's prerogative to secrecy by publishing US diplomatic cables. As a result of these boundary drawings establishing the illegality of WikiLeaks, several companies froze donations to the Web site or stopped them altogether. Operation Payback then morphed into Operation Avenge Assange, which consisted of a distributed denial of service (DDoS) campaign against these companies (Visa, Mastercard, PayPal, Swiss PostFinance, and 
many more). Soon after, and well into 2011, arrests were made in several countries (Netherlands, UK, Australia, Spain, Turkey, and the US) and the FBI issued a statement, in which they reminded the public "that facilitating or conducting a DDoS attack is illegal, punishable by up to 10 years in prison, as well as exposing participants to significant civil liability."23

What had happened between Project Chanology (no arrests) and Operation Payback (at least 80 arrests and several convictions worldwide)? With Operation Payback, designations pertaining to Anonymous as entity changed, and mutually exclusive designations became decisive. When Anonymous began siding with WikiLeaks, the conflict transformed and it became qualitatively different, not because of a changing context, but due to changing communication. The conflict morphed into an antagonism expressive of incompatible relational claims on who legitimately governs the Internet. Now, it was not only about the content of collectively binding designations, but also about political authority expressed through them. In this relational conflict, Anonymous becomes a danger, not as passive projection, but as antagonist actively partaking in its own securitization. Similar to Anonymous, the state is reproduced in this conflict communication as key entity of organizing politically binding designations. At the same time, it is challenged, and in the process subtly changed, by a transforming conflict communication that exposes designations and makes their political binding visible.

First and foremost, Anonymous became visible as being opposed to a highly assertive state authority and designations of the Internet as governance object regulated by diverging rules. At this moment, Anonymous became synonymous with hacktivism. This meant that Anonymous was steadily moving toward an institutionalized social conflict that had long since been securitized. The targets during Operation Payback/Avenge Assange can be (and were) considered to be part of critical infrastructures (the financial sector), the newly defined territory of the cybered state. To Anonymous, the attacks were about illegitimate interferences with freedom of information and freedom of speech. To the state, Anonymous posed a danger to the bases of its prerogatives and "system-relevant" infrastructures, which explains why something as technically simple and consequentially harmless as distributed denial-of-service (DDoS) attacks can be designated as a national security issue in the first place. This relational antagonism was reinforced by other hacktivist activities ascribed to Anonymous, hacks that displayed genuine technical proficiency, mainly conducted by a splitter-group named LulzSec who went after high-level and security-designated targets such as HBGary Federal (a cyber-security contractor) or the CIA Web site. ${ }^{24}$

Furthermore, Anonymous began issuing utterances that were "expected" from a national security threat. The somewhat chilling Anonymous slogan "We are Anonymous. We are Legion. We do not forgive. We do not forget. We will be heard. Expect us" could now be read as a direct challenge to state authorities, especially when coupled with clearly anarchist (antistate/anticapitalist) imagery and action. Ocean metaphors used to talk about the Internet - with clear allusions to piracy and buccaneering - speak to fears in government circles that control over digital data is impossible, particularly once it has been stolen. "Members" of Anonymous also started using the exact same language with which they were being designated as a governance object, that is, calling the state a "cyber-terrorist," and positioning themselves as fighting a "cyber-war" against it. ${ }^{25}$ In this phase, Anonymous also

\footnotetext{
${ }^{23}$ http://www.fbi.gov/news/pressrel/press-releases/warrants_012711. (Accessed August 8, 2014.)

${ }^{24}$ While designations concerning LulzSec were different from those of Anonymous (LulzSec was in fact heavily criticized by many other hackers for their deeds), in the wider antagonistic conflict communication such attributions pertaining to finer distinctions (along a specific issue dimension) are not made-quite the opposite.

${ }^{25}$ A prime example is Operation AntiSecurity, conducted by LulzSec. Communication available at http://pastebin.com/9KyA0E5v. (Accessed August 8, 2014.)
} 
moves closer to a type of resistance that has long been propagating (digital) guerilla tactics (Bey 1991:102). In the writings of digital activists inspired by the anarchist thoughts of Bey and the writings of Deleuze, Guattari, Negri, and others (cf. Critical Art Ensemble 1994), hierarchy is linked to control and power. Resistance to state power must therefore be antihierarchical and resist statism and other forms of mediated agency, in favor of "prefigurative direct action which might render moves toward totalizing forms impotent" (Rossdale 2010:484).

In this last phase, Anonymous' "form" becomes a central element of its existence, for both the collective and the state. Both within the group and in its environment, but also on the side of state actors, there is an obsession with the collective's ontology (or organizational form), which is always directly linked to the question of political agency and ability to pose a threat. Importantly, Anonymous is often observed as without a leader and without any hierarchies: a "decentralized affinity group" ultimately only bound by subscribing to common designations. In fact, this seems to be one of its prime characterizations in all the tales about it. An Anonymous YouTube video titled, "Who is Anonymous?" states that "there is no control, no leadership, only influence-the influence of thought." ${ }^{26}$ Anonymous has memes to discourage anyone from claiming leadership: "Not your personal army" (NYPA) is the phrase that comes up when someone tries to simply tell others what they should be doing (cf. Coleman 2012a). This deliberate amorphousness, this ghost-like existence, has always been a key aspect of Anonymous, the ever-emergent political entity.

\section{Exposing the Limits of State Power}

Once the collective enters conflict with the state, however, it becomes more than that. Its very existence emerges as a direct, "traditional" threat to the state (and its ascribed sovereignty) because it "represent[s] a threat to the spatialized forms of intelligibility and control" (Parikka 2008:116). In other words, Anonymous, as a personification of the "Internet," challenges the ability to designate, and effectively govern, different social spaces. To designate, state power relies on visibilityor on the ability to create such visibility through binding collectivities on its own terms. Anonymous constitutes the danger of that which cannot be made easily visible and that which in consequence cannot be bound and governed by traditional political means. This way, Anonymous moves (is moved) close to a form of political dissent called "leaderless resistance" (Dishman 2005; also Arquilla and Ronfeldt 2001). In our day and age, this resonates immediately with designations of terrorist sleeper cells, and the debate about how to govern them, serving to reinforce the fear of digital protest movement and loss of control. ${ }^{27}$

While the magnetic nature of state designations with regard to cyberspace has been described above, we also claimed that every relational securitization reinforces and challenges, even changes, the state. While its ascribed ontological reality comes with a set of stable/stabilized expectations, it also comes with some unstable or (more recently) de-stabilized ones. Every (new) antagonism also changes and sometimes challenges the image of the state as seemingly bodiless, powerful entity. In fact, any (new) political collectivity is bound by designations of constitutive rules and attributes which challenge existing designations to various degrees between large compatibility and sweeping competition. More importantly, it is their appearance that often makes existing designations visible and thereby establishes a possibility of contestation. In that, they serve a specific function: they create ways for society to observe itself, and add to its self-reflexivity (cf. Luhmann 1997). By

\footnotetext{
${ }^{26}$ http://www.youtube.com/watch?v=x0WCLKzDFpI. (Accessed August 8, 2014.) In 2012 http://www.youtube.com/watch?v=Km8RPcO9ZcY. (Accessed August 8, 2014.)

${ }^{27}$ Under the provisions of the USA PATRIOT Act, computer hacking is listed under the banner of "cyberterrorism."
} 
forcing visibility of designations, social conflict makes fault lines emerge through which societal disagreements become apparent, for example, with regard to who is to be in charge of countering a specific threat and also with regard to how specific threats should be legitimately countered.

The verification of "the state" as powerful (or rather, powerless) governor of territoriality is triggered by the emergence of Anonymous as political actor. Anonymous exposes the limits of state power and is met with an excess of state power in return, aimed toward Anonymous as governance object. Laws relating to cyber-misdeeds are extreme, often covering the mere potential of eventual consequences rather than the actual consequences themselves. Furthermore, the challenge of invisibility posed by Anonymous (and many other digital dangers) is met with vigorous attempts to obtain more surveillance power in cyberspace and makes the attempts to reduce anonymity one of the key points in current cyber-security debates (Du Pont 2001; Deibert 2013). The recent discovery of enormous data collection efforts by governments (PRISM, Tempora), though happening in a much broader context, is proof of this.

More specifically, the proliferation of techniques such as profiling, classification, and surveillance makes the creation of "visibility" of the involved designations a key political issue. "Visibility" is essential for the attribution of agency, of political acts and, ultimately, of decision and responsibility (Huysmans 2011), a fact which is acknowledged by most state representatives. ${ }^{28}$ Techniques of designation that operate on reduced visibility effectively subvert political legitimacy and accountability - and thereby politicize the establishment of visibility. Therefore, the relational antagonism with Anonymous helps to expose sometimes excessive and sometimes hidden state power and makes particular designations visible and thereby contestable.

\section{Conclusion}

This paper has studied a relational process of securitization, highlighting the emergence of social antagonists from communication itself. We looked at how competing designations, which communicate rules and attributes with regard to a governance object, are generative of the visibility of political entities and their ascribed agency - not the other way around. In contrast to many approaches that have implicitly or explicitly conceptualized Othering (and securitization) as a unidirectional process between (active) sender and (passive) receiver, an approach that is based on communication as a basic denominator of any conflict reality can help us understand dynamics that less relational approaches tend to overlook, in particular the unintentional early formation phase of conflicts as well as their escalation/de-escalation.

Indeed, the phenomenon explored in this paper, the multistage emergence of "Anonymous" and its trajectory toward a forceful clash with "the state," can only be fully grasped if opponents are seen as constituted in a specific antagonistic relationship, in short, if the "threat" has a voice of its own and actively partakes in such an (antagonistic) relationship. Without it, only the very last phase of this process could be captured-the one where "the state" securitizes Anonymous, that is, establishes "it" as a security threat and forcefully seeks to govern it. However, to understand the full context of such a securitization, how it is possible,

\footnotetext{
${ }^{28}$ For example, state representatives' statements in defense of the prerogatives to surveillance and secret designations in the context of the United States' PRISM program do not deny the relation between visibility and legitimacy. Rather, by arguing that visibility, to consist in legal and judicial oversight, was actually sufficient, representatives implicitly acknowledge its meaning and significance. See The Washington Post, June 6, 2013, Administration, Lawmakers Defend NSA Program to Collect Phone Records. Available at http://articles.washingtonpost.com/2013-06-06/world/39776923_1_phone-records-surveillance-program-nsa. (Accessed August 8, 2014.)
} 
which aspects seem inevitable, and what this securitization does, we have to move beyond unidirectional "threat-making."

As a collective, Anonymous is bound by a common (though fluctuating) commitment, continuously produced anew through designations. Its appearance as something that can be potentially bound and addressed makes these designations visible. At the same time, the relational securitization of Anonymous-and, we suggest, of many other social and protest movements - challenges the hierarchical logic (and power) of securitization, as it is traditionally understood. Contemporary (fluid) protest movements such as Anonymous actively challenge (state) designations through their own designations, which thus become a form of political resistance (though only partially intentional and as a matter of choice). The logic of designation processes with security implications is that competing designations are challenges toward the ontological base of the state.

The magnetic pull of security-related designations is thus both dangerous and potentially liberating, and of relevance to many conflicts other than the one studied here. It is dangerous because it propels political protest movements or other entities into an antagonistic relationship with the state, which by default often leads to forceful (and violent) reactions, geared toward their dismantling. However, making visible that which tries to stay hidden as a particular form of politicization serves a societal function, as it makes contestation possible in the first place.

There is a distinct possibility of, but certainly no automatism toward, securitization with new designations appearing. Besides constituting entities, new designations also, on principle, emerge with the rise of new governance objects. Often, the latter represent intensely contested issues, of which "the Internet" is but one example. Other new governance objects, such as "the climate," similarly raise controversy.

Protest movements often enable political debate by introducing new distinctions without which reality simply would not be perceived, indeed exist, politically. In a way, therefore, protest movements provide for the condition of possibility of their own political resistance. Understanding the workings and content of designations (and their visibility), then, seems to be the key to understanding social conflict and provides us with an opening toward intentionally deescalating conflict.

\section{References}

Albert, Mathias, Oliver Kessler, and Stephan Stetter. (2008) On Order and Conflict: International Relations and the 'Communicative Turn.' Review of International Studies 34 (Special Issue): $43-67$.

Arquilla, John, And David Ronfeldt. (2001) Networks and Netwars: The Future of Terror, Crime, and Militancy. Santa Monica, CA: Rand Corporation.

BalzacQ, Thierry. (2005) The Three Faces of Securitization: Political Agency, Audience and Context. European Journal of International Relations 11 (2): 171-201.

Barlow, John Perry. (1996) A Declaration of the Independence of Cyberspace. Available at http:// homes.eff.org/ barlow/Declaration-Final.html. (Accessed August 8, 2014.)

Bendrath, Ralf. (2003) The American Cyber-Angst and the Real World - Any Link? In Bombs and Bandwidth: The Emerging Relationship between IT and Security, edited by Robert Latham. New York, NY: The New Press.

Bernstein, Steven, Ned Lebow, Janice Stein, and Steven Weber. (2011) 4chan and/b/: An Analysis of Anonymity and Ephemerality in a Large Online Community. Proceedings of the Fifth International AAAI Conference on Weblogs and Social Media. Available at http://www.aaai.org/ ocs/index.php/ICWSM/ICWSM11/paper/download/2873/4398. (Accessed August 8, 2014.)

Bey, Накім. (1991) T.A.Z. The Temporary Autonomous Zone, Ontological Anarchy, Poetic Terrorism. Brooklyn, NY: Autonomedia.

Bilton, Nick. (2010) One on One: Christopher Poole, Founder of 4chan. The New York Times, March 19. Available at http://bits.blogs.nytimes.com/2010/03/19/one-on-one-christopher-poolefounder-of-4chan/. (Accessed August 8, 2014.) 
Buzan, Barry, Ole Whver, and JaAp de Wilde. (1998) Security: A New Framework for Analysis. London: Lynne Rienner.

Campbell, David. (1992) Writing Security: United States Foreign Policy and the Politics of Identity. Revised. Minneapolis, MN: University of Minnesota Press.

Coleman, Gabriella. (2011) From the Lulz to Collective Action. The New Everyday. Available at http://mediacommons.futureofthebook.org/tne/pieces/anonymous-lulz-collective-action/. (Accessed August 8, 2014.)

Coleman, Gabriella. (2012a) Am I Anonymous? limn Issue Number Two: Crowds and Clouds. Available at http://limn.it/am-i-anonymous/. (Accessed August 8, 2014.)

Coleman, Gabriella. (2012b) Coding Freedom: The Ethics and Aesthetics of Hacking. Princeton, NJ: Princeton University Press.

Coleman, Gariella, and Michael Ralph. (2011) Is It a Crime? The Transgressive Politics of Hacking. Anonymous. Available at http://owni.eu/2011/09/29/is-it-a-crime-the-transgressivepolitics-of-hacking-in-anonymous/. (Accessed August 8, 2014.)

Corry, Olaf. (2013) Constructing a Global Polity. Theory, Discourse and Governance. London: Palgrave MacMillan.

Crenshaw, Adrian. (2011) Crude, Inconsistent Threat: Understanding Anonymous. Available at http://www.irongeek.com/i.php?page=security/understanding-anonymous. (Accessed August 8, 2014.)

Critical Art Ensemble. (1994) The Electronic Disturbance. New York, NY: Autonomoedia.

Deibert, Ronald. (2013) Black Code: Inside the Battle for Cyberspace. Toronto, ON: McClelland and Stewart.

Deibert, Ronald, and Rafal Rohozinski. (2009) Tracking GhostNet: Investigating a CyberEspionage Network. Information Warfare Monitor. Available at http:/ /www.infowar-monitor.net/ 2009/09/tracking-ghostnet-investigating-a-cyber-espionage-network/. (Accessed August 8, 2014.)

Der Derian, James. (1990) The (S) pace of International Relations: Simulation, Surveillance, and Speed. International Studies Quarterly 34 (3): 295-310.

Diez, Thomas, Stephan Stetter, and Mathias Albert. (2006) The European Union and Border Conflicts: The Transformative Power of Integration. International Organization 60 (3): 563-593.

Dishman, Chris. (2005) The Leaderless Nexus: When Crime and Terror Converge. Studies in Conflict E Terrorism 28 (3): 237-252.

Donath, Judith. (1998) Identity and Deception in the Virtual Community. In Communities in Cyberspace, edited by Mark A. Smith and Peter Kollock. London: Routledge.

Doty, Roxanne. (1996) Imperial Encounters: The Politics of Representation in North-South Relations. Minneapolis, MN: University of Minnesota Press.

Du Pont, George. (2001) The Criminalization of True Anonymity in Cyberspace. 7 Michigan Telecomm. Tech. L. Rev. Available at http://www.mttlr.org/volseven/du\%20pont.html. (Accessed August 8, 2014.)

Elliott, DC. (2009) Anonymous Rising. LiNQ 36: 96-111. Available at http://www.linq.org.au/wpcontent/uploads/LiNQ-Vol-36.pdf. (Accessed August 8, 2014.)

Emirbayer, Mustafa. (1997) Manifesto for a Relational Sociology. American Journal of Sociology 103 (2): 281-317.

Guzzini, Stefano. (2000) A Reconstruction of Constructivism in International Relations. European Journal of International Relations 6 (2): 147-182.

Halupka, Max. (2011) The Evolution of Anonymous as a Political Actor. Unpublished Masters Thesis, The Flinders University of South Australia.

Halupka, Max, and Cassandra Star. (2011) The Utilisation of Direct Democracy and Meritocracy in the Decision Making Process of the Decentralised Virtual Community. Anonymous Conference Paper, Australian Political Studies Association Conference, September 26-28.

Himanen, Peкka. (2001) The Hacker Ethic and the Spirit of the Information Age. New York, NY: Random House.

Huysmans, Jef. (2011) What's in an Act? On Security Speech Acts and Little Security Nothings. Security Dialogue 42 (4-5): 371-383.

Jackson, Patrick Thaddeus, and Daniel H. Nexon. (1999) Relations Before States: Substance, Process and the Study of World Politics. European Journal of International Relations 5 (3): 291-332.

Jacobsen, Jeff. (2009) We Are Legion: Anonymous and the War on Scientology. Available at http:// www.lisamcpherson.org/pc.htm. (Accessed August 8, 2014.)

Jordan, Tim. (2008) Hacking: Digital Media and Technological Determinism. Cambridge: Polity Press.

Levy, Steven. (1984) Hackers: Heroes of the Computer Revolution. Sabastopol: O'Reilly Media. 
Lohse, Simon. (2011) Zur Emergenz des Sozialen bei Niklas Luhmann. Zeitschrift für Soziologie 40 (3): 190-207.

Luhmann, NikLas. (1995) Social Systems. Stanford: Stanford University Press.

Luhmann, Niklas. (1997) Die Gesellschaft Der Gesellschaft. Frankfurt am Main: Suhrkamp.

Luhmann, Niklas. (2000) Die Politik Der Gesellschaft. Frankfurt am Main: Suhrkamp.

Lunceford, Brad. (2012) The Rhetoric of the Web: The Rhetoric of the Streets Revisited Again. Communication Law Review 12 (1): 40-55.

McAdam, Doug, Sidney G. Tarrow, and Charles Tilly. (2001) Dynamics of Contention. Cambridge: Cambridge University Press.

Messmer, Heinz. (2007) Contradiction, Conflict and Borders. In Territorial Conflicts in World Society: Modern Systems Theory, International Relations and Conflict Studies, edited by Stephan Stetter. London: Routledge.

Minalache, Adrian. (2002) The Cyber Space-Time Continuum: Meaning and Metaphor. The Information Society 18 (4): 293-301.

Mitzen, Jennifer. (2006) Ontological Security in World Politics: State Identity and the Security Dilemma. European Journal of International Relations 12 (3): 341-370.

Nassehi, Armin. (2002) Politik Des Staates Oder Politik Der Gesellschaft? Kollektivität als Problemformel des Politischen. In Theorie Der Politik. Niklas Luhmanns Politische Soziologie, edited by Kai-Uwe Hellmann, and Rainer Schmalz-Bruns. Frankfurt am Main: Suhrkamp.

Neumann, Iver. (1999) Uses of the Other: "The East" in European Identity Formation. Manchester: Manchester University Press.

Nexon, Daniel H. (2010) Relationalism and New Systems Theory. In New Systems Theories of World Politics, edited by Mathias Albert, Lars-Erik Cederman and Alexander Wendt. Basingstoke: Palgrave Macmillan.

Nissenbaum, Helen. (2004) Hackers and the Contested Ontology of Cyberspace. New Media and Society 6 (2): 195-217.

Olsen, Parmy. (2013) We Are Anonymous: Inside the Hacker World of LulzSec, Anonymous, and the Global Cyber Insurgency. New York, NY: Little, Brown and Company.

Onuf, Nicholas Greenwood. (1991) Sovereignty: Outline of a Conceptual History. Alternatives: Global, Local, Political 16 (4): 425-446.

Parikka, Jussi. (2007) Digital Contagions - A Media Archaeology of Computer Viruses. New York, NY: Peter Lang.

Parikka, Jussi. (2008) Politics of Swarms: Translation between Entomology and Biopolitics. parallax 14 (3): 112-124.

Parikka, Jussi. (2009) Archives of Software: Malicious Code and the Aesthesis of Media Accidents? In The Spam Book: On Viruses, Porn, and Other Anomalies from the Dark Side of Digital Cultur, edited by Jussi Parikka and Tony D. Sampson. Cresskill, NJ: Hampton Press.

PCCIP, President's Commission on Critical Infrastructure Protection. (1997) Critical Foundations: Protecting America's Infrastructures. Washington, DC: US Government Printing Office.

Phillips, Whitney. (2013) The House That Fox Built: Anonymous, Spectacle, and Cycles of Amplification. Television Ẽ New Media 14 (6): 494-509.

Rolfe, BretT. (2005) Building an Electronic Repertoire of Contention. Social Movement Studies 4 (1): $65-74$.

Rossdale, Chris. (2010) Anarchy Is What Anarchists Make of It: Reclaiming the Concept of Agency in IR and Security Studies. Millennium 39 (2): 483-501.

Underwood, Patrick. (2009) New Directions in Networked Activism and Online Social Movement Mobilization: The Case of Anonymous and Project Chanology. Unpublished Masters Thesis. Available at http://etd.ohiolink.edu/view.cgi?acc_num=ohiou1244228183. (Accessed August 8, 2014.)

Vichot, Ray. (2009) Doing It for the Lulz? Online Communities of Practice and Offline Tactical Media. Unpublished Masters Thesis, School of Literature, Communication, and Culture, Georgia Institute of Technology.

Walker, Rob. (2011) Recognizably Anonymous: How Did a Hacker Group That Rejects Definition Develop Such a Strong Visual Brand? Slate, December 8. Available at http://www.slate.com/ articles/arts/design/2011/12/

guy_fawkes_mask_how_anonymous_hacker_group_created_a_powerful_visual_brand.html. (Accessed August 8, 2014.)

Wall Street Journal. (2012) Alert on Hacker Power Play: U.S. Official Signals Growing Concern Over Anonymous Group's Capabilities, February 21: A2(1).

Yen, Alfred C. (2003) Western Frontier or Feudal Society? Metaphors and Perceptions of Cyberspace. Berkeley Technology Law 17 (4): 1207-1264. 